\title{
Currículos e agenciamentos do devir: trânsitos ao redor de Deleuze na delimitação da infância a partir de $O$ Emílio de Rousseau
}

\author{
Tiago Alexandre Fernandes Almeida ${ }^{\text {Orid, }} \star$ \\ Escola Superior de Educação de Lisboa, Benfica, Lisboa, Portugal
}

Resumo

\begin{abstract}
Este artigo tem como objetivo questionar, a partir da leitura de Emílio, ou Da Educação, de Rousseau, como é que os conceitos de agenciamento e devir possibilitam pensar uma delimitação da infância que inscreve processos de subjetivação na forma como adultos e crianças se relacionam, e como é que esses processos ainda nos acompanham na contemporaneidade. Questiona-se como é que a operacionalização do agenciamento, coletivo e múltiplo, mas também individual e particular, UMA-CRIANÇA-DEVIR-ADULTO, tem no seu interior um adulto por vir que, na multiplicidade constitutiva do que foi o seu "estar-a-ser-criança" incorpore o "governo de si". Metodologicamente, dialoga-se com a obra de Rousseau a partir dos conceitos referidos anteriormente e procura-se traçar uma genealogia de uma ideia possivel de criança que ainda hoje se mantém atual. Conclui-se deixando em aberto a possibilidade de a infância constituir um tempo e um espaço que valorize o "estar-a-ser-criança" (descobrir, brincar, questionar), conscientes de que existe tempo para concluir o projeto "uma criança devir adulto".
\end{abstract}

Palavras-chave: agenciamento; devir; criança; infância.

\section{Curriculum and Agency of Becoming: Deleuze and the delimitation of childhood from Rousseau's Emile}

\begin{abstract}
This article aims to analyze, from the reading of Rousseau's Emile, or On Education, how the concepts of agency and becoming allow us to think about delimitation of childhood that has inside subjectivation processes of how adults and children relate between each other and how these processes are visible in contemporary times. This work questions how is the operationalization of an agency, collective and multiple, but also individual and particular, A-CHILD-BECOMING-ADULT. It has in its interior an adult to be that, in the constitutive multiplicity of what was previously its "being-a-child" and in its present individuality, incorporates "self-government". Methodologically, this paper dialogue with Rousseau works from the concepts mention earlier and try to express a genealogy of a possible idea of what a child is in nowadays. We conclude by leaving open the possibility of childhood to be a time and a space that enhances the "being-a-child" (discover, play, questioning), aware that there is time to complete the project "a child becoming an adult".
\end{abstract}

Keywords: agency; becoming; child; childhood.

\section{Porque estão aqui também manias e opiniões que são minhas; por elas se mostra aquilo em que acredito, não o que os outros devem acreditar. Não viso aqui descobrir-me a mim próprio; outro serei porventura amanhã, se novo estudo me mudar (MONTAIGNE, 1993, p. 37).}

O objetivo deste trabalho é problematizar o lugar da criança em Emílio, ou Da Educação, de Rousseau (1762/1979), cuja escolha se justifica por ter inaugurado uma certa visão da infância ou das "infâncias" que ainda nos acompanha na contemporaneidade. Pretende-se, além disso, questionar como é que o discurso produzido nessa obra reverbera, à época em que foi escrito, uma certa forma de ser adulto representada pela própria figura de Rousseau. Esta reflexão procura manter em andamento essa questão maior da nossa civilização e que consiste em saber: "o que é uma criança?"

Ao propor-me tratar de uma tão complexa questão não é por procurar encontrar para ela respostas definitivas, mas antes para poder continuar a pensar sobre como este tema se apresenta à nossa frente. Ou seja, tomei a liberdade de reler esta obra consagrada, através de um

\footnotetext{
^Endereço para correspondência: Escola Superior de Educação de Lisboa. Departamento de Ciências Humanas e Sociais - Campus de Benfica. R. Carolina Michaelis de Vasconcelos, 1549-003 - Lisboa, Portugal.E-mail: tiagoa@eselx.ipl.pt
}

problema e de uma filiação teórica que me permitem continuar a problematizar a relação dos adultos com as crianças pequenas e com o seu "por vir".

Para tanto, mobilizarei os conceitos de "agenciamento" e "devir" muito presentes na dupla Gilles Deleuze e Félix Guattari (2007, p. 639), designadamente em Mil Planaltos. A intenção de operacionalizar este par na tentativa de responder a "o que é uma criança?" supõe o erguer de uma grande cartografia (DELEUZE, 2005) do dispositivo da infância, da qual este texto pretende ser uma pequena parte. Não se trata, por isso, de uma tentativa de definir um momento fundador, desta ou daquela forma de conceber a infância, mas, antes, de pensar como é que esse problema se coloca perante Rousseau e sua obra. Agenciamento e devir; foi com essas lentes teóricas que reli Emílio, e com elas vinculei-me a três simples regras neste trabalho:

- procurar em Emílio excertos que adiram e façam sobressair a dupla conceptual que tomo;

- elaborar, a partir desse arquivo, eixos de análise que permitam problematizar a questão de partida;

- estabelecer entre esses eixos uma narrativa que traduza um diagnóstico que comunique diretamente com o presente. 
Espero, por isso, que o resultado desta investigação evidencie modos de funcionamento que perpassem a forma como ainda nos relacionamos com as crianças e, assim, permita continuar a pensar a delimitação do que é uma criança na atualidade, possibilitando um exercício de pensamento de análise crítica sobre o que se naturalizou e, ao mesmo tempo, encontrar linhas de fuga e descontinuidades face à tradição incorporada. Numa palavra, trabalhar para um novo "amanhã" da infância. No dizer de Deleuze e Guattari (2007, p. 302),

A história das ideias nunca devia ser contínua, devia manter semelhanças, mas também descendências ou filiação, para limitar-se a marcar limiares que atravessam uma ideia, as viagens que faz, que mudam a natureza ou o objecto. Ora, eis que as relações objectivas dos animais entre eles foram retomadas em certas relações subjectivas do homem com o animal, do ponto de vista de uma imaginação coletiva, ou do ponto de vista do entendimento social.

Dito de outra forma, este exercício configura uma possibilidade de análise, entre tantas outras possíveis, de pensar "semelhanças", "descendências" e "filiações" que "marcam os limiares que atravessam a ideia" do que é uma criança.

\section{Agenciamento e devir: o problema teórico}

De certo modo, o termo agenciamento permite problematizar, dialogicamente, o que é enunciado e a forma como esses enunciados se operam em processos de subjetivação e de constituição de sujeitos. Neste caso específico, interessa-me analisar como é que o agenciamento permite ver operacionalizar-se, em Rousseau, a subjetivação do sujeito em sujeito-criança, ou seja, como o sujeito se torna criança, constituindo-se como tal, com modos de ser e agir esperados. Dito de outra forma, como é que no texto Emílio, ou Da Educação Rousseau vai delimitando o que pode e o que não pode uma criança ser, e como, com esse discurso, nos vai propondo, inteiramente à distância, uma definição do que é uma criança que reconhecemos como próxima. É nesta perspectiva de fazer recuar no tempo uma genealogia do presente - sublinhe-se que a obra foi publicada pela primeira vez em 1762 - que recorro à ferramenta teórica do agenciamento.

\section{Deleuze e Guattari (2007, p. 641) referem que}

As regras concretas de agenciamento operam, pois, segundo [...] dois eixos: por um lado, qual a territorialidade do agenciamento, quais são o regime de signos e sistema pragmático? Por outro lado, quais são os pontos de desterritorialização e as máquinas abstractas que efectuam? Há uma tetravalência do agenciamento: 1) conteúdo e expressão; 2) territorialidade e desterritorialização.

O problema que aqui é colocado por Deleuze e Guattari, ver-se-á, é contíguo ao conceito dispositivo de Foucault (DELEUZE, 2016, p. 359), no sentido em que este procura caracterizar como é que as "máquinas abstratas", que podem corresponder a uma heterogeneidade de autoridades, agências e ciências, exercem uma autoridade de Estado na configuração de certas formas de ser. Existe, por isso, um "potencial subjetivante nos agenciamentos", isto é, no caso em apreço, que são traduzidos em práticas e formas concretas de enunciação acerca do que é e do que deve ser uma criança. Práticas e formas de enunciação que nos colocam perante o seguinte problema: como é que a linguagem e o discurso se unem para produzir formas de relacionamento com as crianças que estão, muitas vezes, para lá do que é enunciado? Nas Conversações o próprio Deleuze (1972-1990/2008, p. 109) clarifica que

É nos agenciamentos que encontraríamos focos de unificação, nós de totalização, processos de subjetivação, sempre relativos, a serem sempre desfeitos a fim de seguirmos ainda mais longe uma linha agitada. Não buscaríamos origens mesmo perdidas ou rasuradas, mas pegaríamos as coisas onde elas crescem, pelo meio: rachar as coisas, rachar as palavras. Não buscaríamos o eterno, ainda que fosse a eternidade do tempo, mas a formação do novo, a emergência ou o que Foucault chamou de 'a atualidade'.

Sintetizando, embora o trabalho de Deleuze e Guattari procure encontrar "linhas de fuga" que ampliem e rompam com a leitura uniformizante e universal dos "acontecimentos", interessa-me pensar, a partir deste potencial subjetivante do agenciamento, como é que Rousseau estava, simultaneamente, a enunciar uma definição do que é uma criança e, ao mesmo tempo, a delimitar uma territorialidade que ainda hoje se encontra na forma como enunciamos e nos relacionamos com a infância e a sua educação. Ou seja, Emílio, ou Da Educação transporta no seu interior um agenciamento que se traduz num regime de signos coletivo de ordem pragmática (LAPOUJADE, 2015, p. 202-203) sobre o que é uma criança. Estamos perante um agenciamento duplo, isto é, não se trata apenas "de uma concretização desta ou daquela máquina abstrata”, mas também de uma enunciação e uma definição do termo a que se refere, neste caso o termo: UMA CRIANÇA. Pensar sobre o agenciamento do termo UMA CRIANÇA implica pensar também naquilo que dele devém.

Quando falam em devir, Deleuze e Guattari (2007, p. 305) referem-se a um "tornar-se em, numa passagem de um estado a outro que não é uma correspondência de relações", nem "história", pois "a história designa somente o conjunto das condições, por mais recentes que sejam, das quais desvia-se [sic] a fim de 'devir', isto é, para criar algo novo" (DELEUZE, 1972-1990/2008, p. 211). Deleuze (1972-1990/2008, p. 214) propõe a seguinte explicação nas Conversações:

As minorias e as maiorias não se distinguem pelo número. Uma minoria pode ser mais numerosa que uma maioria. $\mathrm{O}$ que define a maioria é um modelo ao qual é preciso estar conforme: por exemplo, o europeu médio adulto macho habitante das cidades [...] Ao passo que uma minoria não tem modelo, é um devir, um processo. Pode-se dizer que a maioria não é ninguém. Todo mundo, sob um ou outro aspecto, está tomado por um devir minoritário que o arrastaria por caminhos desconhecidos caso consentisse em segui-lo. Quando uma minoria cria para si modelos, é porque quer tornar-se majoritária, e sem dúvida isso é inevitável para sua sobrevivência ou salvação (por exemplo, ter um Estado, ser reconhecido, impor seus direitos). Mas sua potência provém do que ela soube criar, e que passará mais ou menos para o modelo, sem dele depender. O povo é sempre uma 
minoria criadora, e que permanece tal, mesmo quando conquista uma maioria: as duas coisas podem coexistir porque não são vividas no mesmo plano.

Esta referência a minorias e maiorias permite pensar que há uma trajetória a duas mãos no devir. A partir desta perspectiva, creio que existe em todos os sujeitos, por um lado, um devir minoritário e, por outro, um devir maquínico, um devir maioritário que é totalizante e totalizador, uma prática da uniformização e normalização, a que ninguém escapa se pensarmos na vida que se gera no interior das instituições de educação e ensino. Não falo no sentido de exprimir uma oposição deliberada e intencional, mas num movimento que se consagra através de estratos de história que definem a infância atual e projetam o seu futuro. Em certo sentido, penso que esta formulação capta a tensão criança-adulto que procuro estudar e que se traduz na enunciação do "estar-a-ser-criança" a partir de um "tornar-se adulto". Dito de outra forma, este conceito de devir abre a possibilidade do sujeito-criança representar, em si mesmo, um agenciamento coletivo que tem no seu interior o devir-adulto, o tornar-se adulto, cuja enunciação é de novidade, de um outro novo, de um "povo por vir", mas que concretiza, afinal, a hegemonia do projeto do adulto de cada uma das "atualidades", de cada um dos "tempos" presentes.

Finalizo, reforçando que os dois conceitos estabelecem entre si um diálogo que possibilita considerar como individualização e totalização se relacionam e se interligam através de um conjunto de discursos de enunciação e práticas discursivas, simultaneamente, produto e produtores de sujeitos-criança. É, pois, através do diálogo entre este par que me proponho estudar o "agenciamento" uma-criança-“devir"-adulto a partir de Emílio, ou Da Educação, de Rousseau.

\section{O problema da infância: um apontamento histórico}

Uma das questões instigantes que se desdobra da pergunta de partida é esta: quando é que uma criança deixa de ser uma criança? Ou ainda: quais os limites que separam quem é uma criança de quem já não é?

Vale a pena determo-nos um pouco sobre essas questões. Na sua obra $A$ criança e a vida familiar no Antigo Regime, Ariès (1988, p. 182-183) diz-nos que o "sentimento da infância", que corresponde a uma "consciência da especificidade infantil" e que a distingue do "adulto" e do "adulto jovem", foi "descoberto", grosso modo, entre os séculos XVI e XVII. Antes, na sociedade medieval, no momento em que a criança conseguia sobreviver sem os cuidados "constantes da mãe, da sua ama ou da sua aia, passava a pertencer à sociedade dos adultos e deixava de se distinguir dela" (ARIÈS, 1988, p. 182-183).

Como é sobejamente conhecido, Ariès fala-nos que esta "descoberta" trouxe, também ela, um duplo "sentimento da infância". Um primeiro a que chamou de "criança-brinquedo" e um outro, que se instalou de forma "definitiva e imperativa a partir do fim do século XVII”, pelo qual, "embora com muitas reticências e atrasos, a criança é separada dos adultos e isolada numa espécie de quarentena antes de ser lançada ao mundo": a escolarização.
Tanto a criação de um lugar à parte para a criança quanto a sujeição da infância a uma disciplina devem ser interpretadas como uma das facetas da grande moralização dos homens levada a cabo pelos reformadores católicos ou protestantes, eclesiásticos, juristas ou homens de estado. Mas não teria sido possível concretizá-la sem a cumplicidade sentimental das famílias, e é esta a segunda abordagem do fenômeno, na qual gostaria de insistir. A família passou a ser aquilo que antes não era: um lugar de afeição necessária entre os esposos e entre pais e filhos. Esta afeição exprime-se sobretudo através da importância agora atribuída à educação. Já não se trata apenas de estabelecer os filhos em função da honra e da fortuna. Sentimento inteiramente novo: "os pais interessam-se pelos estudos dos filhos e acompanham-nos com uma solicitude corrente nos séculos XIX e XX, mas outrora desconhecida" (ARIÉS, 1988, p. 12).

Parto do princípio de que há neste período uma convergência que evidencia o que parece ser o início de um projeto comum, à família, à sociedade e ao Estado, para as crianças. Para estas instituições nucleares da vida em relação, as crianças encerravam em si uma ideia de "futuro" que importava cuidar e cuja salvaguarda e concretização eram conseguidas através da educação e da escolarização. Já não bastava deixar de precisar de cuidados, seria necessário que as crianças fossem protegidas e educadas mesmo antes de passarem pelas instituições que ritualizam a sua passagem para o mundo adulto: a escola ou o colégio. De certo modo, as crianças passaram a ser, concomitantemente, presente e futuro, e coube à educação e à escolarização garantir esse patrimônio.

Um problema que passou a atravessar, desde aí, as conversas em torno da educação das crianças tem sido, precisamente, o que deve ou não deve ser expresso na educação escolar e, amiúde, quando é que esse processo de educação e escolarização estará ou não concluído. Se para esta discussão convocarmos o nosso problema de partida, poderemos pensar que o agenciamento, na sua dimensão de "atualidade", e o devir, na sua potência futura, são problemas contíguos ao que se acaba de enunciar.

Pertencemos a tais dispositivos e agimos neles. À novidade de um dispositivo relativamente aos anteriores chamamo-la sua atualidade, nossa atualidade. O novo é o atual. O atual não é o que somos, mas antes o que devimos, o que estamos em via de devir, ou seja, o Outro, nosso devir-outro. Em todo o dispositivo, é preciso distinguir o que somos (o que já nem somos mais) e o que estamos em via de devir: "a parte da história e a parte do atual". A história é o arquivo, o desenho do que somos e deixamos de ser, ao passo que o atual é o esboço do que devimos. De modo que a história ou o arquivo é o que ainda nos separa de nós mesmos, ao passo que o atual é este outro com o qual já coincidimos (DELEUZE, 2016, p. 363).

Concluo que o mais interessante estará, talvez, em perceber que essas afirmações podem ser aduzidas a épocas e realidades sociopolíticas distintas. Donde o romance pedagógico escrito por Rousseau traduz uma oportunidade de pensar as tensões entre presente e futuro e entre criança e adulto, uma vez que Emílio, ou Da 
Educação retrata o paradoxo de querer "educar fora da sociedade para a sociedade" (ABBAGNANO; VISALBERGHI, 1981, p. 472). É sobre a própria "educação" da criança Emílio que me debruçarei em seguida, fazendo variar o problema teórico que enunciei na seção anterior sobre a leitura do texto rousseauniano.

\section{Rousseau e Emílio enquanto criança}

O livro Emílio, ou Da Educação, de Rousseau , é uma obra frequentemente associada à "descoberta" e expressão de uma visão de criança e de educação que acompanha os ideais iluministas dos séculos XVII e XVIII. Esse texto é, seguramente, um marco relevante no entendimento que temos acerca da socialização institucional das crianças e, também, da emergência de muitas das propostas pedagógicas que se lhe seguiram. Não o procuro apresentar como um texto fundador, mas assumo que é, seguramente, um momento congregador de vários discursos que se vinham afirmando e, ao mesmo tempo, uma plataforma de proveniência do presente. Rousseau não esconde a influência que outros autores tiveram na sua obra, e Emílio acaba por refletir o investimento e interesse pela educação que à época se vivia. Foi, e ainda é, considerada uma obra de caráter paradoxal, o que o próprio Rousseau reconheceu, contendo no seu interior uma permanente tensão dialógica entre necessidade e liberdade, coração e razão, indivíduo e Estado, conhecimento e experiência, articulações cuja acomodação se apresenta difícil ainda nos nossos dias.

Os cinco livros de Emílio acompanham o desenvolvimento do aluno desde o nascimento até o matrimônio. Os dois primeiros tratam do período que vai do nascimento aos 12 anos, o terceiro compreende o período entre os 13 e 15 anos, o quarto aborda a chegada da "racionalidade" a partir dos 16 anos, e o quinto a inserção de Emílio na vida social e o seu matrimônio. Trata-se de uma obra reconhecida, entre outras coisas, por colocar a criança no centro do processo educacional e, a meu ver, ao fazê-lo, Rousseau evidencia um paradoxo constante entre o que é uma criança no presente e o que ela deve tornar-se no futuro. Isso mesmo é captado por Abbagnano e Visalberghi (1981, p. 472-473) quando referem que um dos problemas presentes na obra de Rousseau, e especificamente em Emílio, ou Da Educação, é o de responder à seguinte questão: como será "possível educar o indivíduo a pensar em termos democráticos, isto é, em termos de vontade geral, numa sociedade que não seja já fundada sobre a vontade geral, isto é, ainda que não seja democrática?”. Tal questão desdobra-se numa outra, que é saber como é possível educar um sujeito para devir numa sociedade que não seja já fundada nesse devir, quero dizer, que não seja fundada numa certa "atualidade" ou "contemporaneidade" que se projeta como futuro.

Para além dos vários problemas e das múltiplas leituras já realizadas por outros investigadores sobre o livro Emílio, ou Da Educação, gostaria de propor algumas variações.

A primeira parte da constatação de que Rousseau se dirige à infância já como um domínio tendencialmente específico e delimitável. Nesse sentido, há nele uma consciência do limiar, do estar "entre-tempos" da criança. Refere-se diretamente a um período de vida que não se conhecia até então e que importaria muitíssimo conhecer. É precisamente essa essencialidade, essa especificidade e essa transição específica que Rousseau pretende estudar ao procurar inscrever a infância como um problema de estudo.

Não se conhece a infância: com as falsas ideias que dela temos, quanto mais longe vamos mais nos extraviamos. Os mais sábios apegam-se ao que importa que saibam os homens, sem considerar que as crianças se acham em estado de aprender. Eles procuram sempre o homem na criança, sem pensar no que esta é, antes de ser homem. Eis o estudo a que mais me dediquei a fim de que, ainda que seja meu método quimérico e falso, possam aproveitar minhas observações. Posso ter muito mal visto o que cabe fazer; mas creio ter visto bem o paciente que se deve operar. Começai portanto estudando melhor vossos alunos, pois muito certamente não os conheceis e se lerdes este livro tendo em vista esse estudo, acredito não ser ele sem utilidade para vós (ROUSSEAU, 1762/1979, p. 8).

A segunda variação, que decorre da primeira, é que urge proteger e "isolar" a infância; é necessário que a mãe de Emílio se afaste do "caminho trilhado" e proteja "o arbusto nascente contra as opiniões humanas".

É a ti que me dirijo, terna e previdente mãe, que te soubeste afastar do caminho trilhado e proteger o arbusto nascente contra o choque das opiniões humanas. [...]. Estabelece, desde cedo, um cinto de muralhas ao redor da alma de tua criança. Outro pode assinalar o circuito mas só tu podes erguer o muro (ROUSSEAU, 1762/1979, p. 11).

Penso que esse excerto de Rousseau expressa uma ideia que merece reflexão. A criança, ou melhor, a sua "alma", necessita de ser protegida das "opiniões humanas". E esta é a terceira variação que considero relevante e que dá sentido às duas anteriores: a especificidade que confere à criança a necessidade de proteção do "caminho trilhado" é a sua "alma". Esta necessidade de "proteção" de uma certa essencialidade da "alma" da criança perpassa toda a obra e há, para sua segurança e resguardo, necessidade absoluta do seu confinamento, necessidade de vigiar e orientar o seu desenvolvimento e de o entregar a quem o possa e saiba conduzir - neste caso, o próprio Rousseau, na figura de mestre. Existe, parece-me, uma clivagem sempre em vias de se concretizar nesta premissa. Por um lado, a criança não está preparada para o mundo e, por outro, o mundo não está preparado para a criança. Criança e homem devem ser separados (e aqui homem traduzir-se-á por adulto). Como se, a fim de preparar o mundo para receber a criança, fosse necessário esperar pela criança que se está a formar, já que o contato precoce e antecipado produziria "frutos precoces", que não teriam "maturação nem sabor" e não tardariam "em corromper-se" (ROUSSEAU, 1762/1979, p. 60). Rousseau não propôs uma forma de solucionar o problema, de operar o trabalho de afinamento da "alma", mas deixou claro que "os homens se amanham pela educação", e que esta provem tanto da "natureza" e das "coisas" como do próprio "homem". Em certo sentido, estes três pilares da educação sobre os quais assentaria a educação e a ne- 
cessidade de proteção "contra o choque das opiniões humanas", reenunciavam uma dimensão estoica e cética na formação da criança: é necessário formar opinião pelas próprias coisas, e a única coisa que está ao alcance do homem é o sensível (HADOT, 1999).

Essa educação nos vem da natureza, ou dos homens ou das coisas. O desenvolvimento interno de nossas faculdades e de nossos órgãos é a educação da natureza; o uso que nos ensinam a fazer desse desenvolvimento é a educação dos homens; e o ganho de nossa própria experiência sobre os objetos que nos afetam é a educação das coisas (ROUSSEAU, 1762/1979, p. 12).

No fundo, quando o autor estabelece este gesto de confinamento e moratória, instala um paradoxo: como, simultaneamente, proteger e educar para o mundo dos homens e a partir dele se a criança deve ser protegida do "caminho trilhado"? Penso que aqui há uma semelhança entre o que Rousseau e outros autores anteriores, como Comênio e Locke ou os reformadores protestantes Lutero e Calvino do século XVI, sob perspectivas diferentes, enunciavam. Por um lado, uma crítica sistemática aos "caminhos trilhados", que nos é hoje tão próxima e, por outro, uma tentativa de definir o que convém à educação do homem e do Estado. No entanto, embora estes dois gestos possam ser considerados próximos, Rousseau parece propor algo mais, o esboço de uma essencialidade da "alma" infantil e do que ela necessita para se manter fiel à "meta da natureza".

Então, seja pela especificidade do "estar-a-ser" criança, pelos perigos que o mundo do homem oferece, ou pela necessidade de "moldá-la a seu jeito como uma árvore de seu jardim", há a necessidade de um "isolamento da infância", de uma delimitação que institui uma especificidade que a separa dos adultos. A variação que se encontra é uma certa emergência do "sujeito-criança" a partir do que ela é, ou seja, desenvolve-se uma narrativa que agencia, ao mesmo tempo, a necessidade de "proteção" e "segurança", sem atribuir a este "sujeito-criança" uma especificidade concreta, e instala uma certa ideia de "ser criança". A meu ver, nesta obra de Rousseau propõe-se a grande demanda civilizacional de "conhecer a infância" a partir do que ela é, sem, todavia, se afirmar explicitamente uma resposta. Se quisermos simplificar, uma ideia que encontra eco em Emílio é que a criança, pela essencialidade da sua "alma", precisa ser protegida do mundo, enquanto tal, para voltar, mais tarde, "ao mundo como homem integrável no mundo". "Deplora-se o estado da infância; não se vê que a raça humana teria perecido se o homem não começasse sendo criança." (ROUSSEAU, 1762/1979, p. 12).

Ou seja, já não basta instruir a criança a partir da entrada na escola, é necessário "moldá-la" e "protegê-la" desde o nascimento para preservar e aprender a ocupar-se da sua "alma" (ROUSSEAU, 1762/1979, p. 8-12). No fundo, enquanto os seus contemporâneos, também interessados na educação, se ocupam de "produzi-la" com instrumentos, receituários e didáticas para remodelar o homem, tornando-o um humanista, um bom cristão, um cavalheiro, um bom cidadão, Rousseau ocupa-se de pensar, a partir do "ser-criança" e da sua essencialidade, como manter a sua "natureza" para mais tarde iniciar a sua "educação" formal.

$\mathrm{Na}$ ordem natural, sendo os homens todos iguais, sua vocação comum é o estado do homem; e quem quer seja bem educado para esses, não pode desempenhar-se mal dos que com esse se relacionam. Que se destine meu aluno à carreira militar, à eclesiástica ou à advocacia pouco me importa. Antes da vocação dos pais, a natureza chama-o para a vida humana. Viver é o ofício que lhe quero ensinar. Saindo de minhas mãos, ele não será, concordo, nem magistrado, nem soldado, nem padre; será primeiramente um homem. Tudo o que um homem deve ser, ele o saberá, se necessário, tão bem quanto quem quer que seja; e por mais que o destino o faça mudar de situação, ele estará sempre em seu lugar. Occupavi te, Fortuna, atque cepi; omnesque aditus tuos interclusi, ut ad me aspirare non posses (ROUSSEAU, 1762/1979, p. 15).

O que penso que Rousseau institui é um paradoxo entre o "estar-a-ser" na condição do que se pretende formar. Ele escreve sobre o "estar-a-ser-criança", sobre a sua especificidade, dirigindo-se, simultaneamente, ao que se deve preservar na alma infantil para formar o homem. Repare-se que Rousseau se refere ao direito de a criança "ser-criança", mas não lhe reconhece o lugar de homem. Eis uma citação que tenta capturar esta incongruência:

O homem avisado sabe manter-se em seu lugar; mas a criança, que não conhece o dela, nele não pode manter-se. Ela tem, entre nós, mil soluções para sair dele; cabe aos que a governam mantê-la em seu lugar e a tarefa não é fácil. Ela não deve ser nem animal nem homem e sim criança mesmo; é preciso que sinta sua fraqueza e não que com ela sofra; é preciso que peça e não que mande. Só se acha submetida aos outros por causa de suas necessidades e porque os outros veem melhor do que ela o que lhe é útil, o que pode favorecer ou prejudicar sua conservação. Ninguém tem o direito, nem mesmo o pai, de mandar a criança fazer algo que não lhe seja útil (ROUSSEAU, 1762/1979, p. 54).

Para além do "lugar da criança", Rousseau acrescenta neste parágrafo duas novas ordens de relação: a de governo e a de utilidade. Novas não na sua dimensão absoluta, mas porque alimentam uma prática que é, simultaneamente, atribuída às figuras de socialização e à própria criança. A ama ou o mestre governam a criança para que ela aprenda a governar, por si mesma, os seus impulsos, desejos e necessidades. Acrescente-se que a "utilidade" pode ser vista como aquilo que a criança precisa saber e saber-fazer para se ocupar de si, para se conhecer, isto é, ela deve aprender o "ofício" do governo de si (Ó, 2006), numa relação com o mestre, para, progressivamente, se aproximar do autodomínio, do controle permanente da sua "vontade particular". Esta é a quarta ideia que gostaria de destacar: a proteção da alma, da especificidade da infância, num gesto de confinamento, visa que Emílio aprenda a ocupar-se de si, da sua "vontade particular". Define-se, logo a partir do nascimento, um dispositivo, um agenciamento, de "autogoverno", de governamentalidade (FOUCAULT, 2010) a partir do direito conferido a Emílio de "ser-criança".

Fractal, Rev. Psicol., v. 30 - n. 3, p. 302-309, 2018 
Se quisermos sintetizar, o "sujeito-criança" Emílio tem o direito de "ser criança" e, enquanto tal, de aprender a "governar" a sua "vontade particular" e de fazer "o que lhe é útil". Tem direito a uma moratória para aprender a "conhecer-se a si próprio" e a "cuidar de si" (FOUCAULT, 2006, p. 13) antes de poder ser escolarizado. É preciso "cuidar da alma" de Emílio para que ele se ocupe dela antes de se dar início à sua educação formal e para que possa, então, não porque seja obrigado, mas porque quer, "obedecer à voz da razão" "sob a suprema direção da vontade geral" (ROUSSEAU, 1762/1979, p. 401).

Não imaginais como com vinte anos Emílio pode ser dócil. Como pensamos diferentemente! Não concebo como pôde ser nos dez anos; pois que domínio podia ter sobre ele nessa idade? Precisei de quinze anos para adquiri-lo. Não o educava então, preparava-o para ser educado. Ele o é agora bastante para ser dócil; reconhece a voz da amizade, sabe obedecer à razão.

Deixo-lhe, é verdade, a aparência da independência, mas nunca me foi mais obediente, porque o é por querer sê-lo. Enquanto não pude tornar-me senhor de sua vontade, eu o fui de sua pessoa; não o largava um instante. Agora eu o deixo por vezes só, porque o governo sempre (ROUSSEAU, 1762/1979, p. 285)

Temos, então, que Rousseau atribui à infância uma essencialidade "natural" que confere ao sujeito o direito de "ser criança" enquanto aprende a cuidar da sua "alma", a governar a sua "vontade particular" e a fazer "o que lhe é útil". Penso que podemos questionar: qual é, afinal, o momento em que a criança passa a ser outra coisa?

A partir do livro quarto, Rousseau (1762/1979, p. 173) fala-nos de um sujeito que "não é nem criança nem homem e não pode pegar o tom de nenhum dos dois". Há um limbo que marca esta passagem, mas que é atravessado por um mesmo princípio de conhecimento e governo de si, como expressam, a meu ver, as três máximas propostas no quarto livro. Ao mestre, cabe a "arte de prolongar" a infância para que Emílio aprenda o "governo das suas paixões” (ROUSSEAU, 1762/1979, p. 193).

Creio que a premissa que falta, a última desta análise, é que Rousseau, quando fala da criança, fá-lo em espelho consigo próprio. Mestre e Emílio refletem-se no próprio autor do texto. Ou seja, o homem, o adulto de quem Rousseau fala, à semelhança do mestre, é ele próprio, e Emílio é a criança que irá devir no adulto que ele, Rousseau, representa. É quando o mestre reconhece em Emílio a sua "obra", quando o reconhece como "o mesmo", que abdica da sua "autoridade" de governo sobre a alma de Emílio (ROUSSEAU, 1762/1979, p. 419). O mesmo é dizer que Emílio é homem-adulto quando representa o ideal de família e Estado que o próprio Rousseau definiu e apresenta, por exemplo, em The social contract (1762/2004). Este reconhecimento de Emílio como "o mesmo" é assinalado pelo fim da autoridade do mestre sobre ele, ou seja, esbate-se, termina a relação de poder entre ambos porque o mestre dela abdica. São agora o mesmo; Emílio governa a sua "alma", porque aprendeu a fazê-lo à semelhança de seu mestre. Isso é expresso neste excerto:
Caro Emílio, um homem precisa a vida inteira de conselhos e de guia. Fiz o máximo em meu poder para cumprir esse dever convosco; aqui termina minha longa tarefa e inicia-se a de outro. Abdico hoje a autoridade que me destes e eis vosso governante doravante (ROUSSEAU, 1763/1979, p. 419).

Emílio não é mais "suiejto-criança", é o sujeito-homem, o adulto que Rousseau representa e projeta como o "futuro" que importa cuidar. O sujeito-adulto toma o lugar do sujeito-criança quando o "ato de criação" se conclui e o "criador" se revê, "contemplando neles a [sua] obra, [...] tomado de um enlevo que faz palpitar o coração!” (ROUSSEAU, 1763/1979, p. 419).

\section{Onde se esboça uma conclusão sobre como a educação de Emílio nos fala na atualidade}

Poder-se-á discutir sempre o caráter paradoxal do romance de Rousseau, ou até mesmo a sua dimensão idealista, mas, ao convocarmos os processos de constituição de Emílio-criança em Emílio-homem, colocam-se, parece-me, entre todos os problemas já encontrados em trabalhos anteriores, outros quatro, a partir dos quais me proponho relançar a questão de partida.

O primeiro é que a criança tem uma especificidade, uma "alma" que importa cuidar para melhor ser instruída. É a partir da infância, do nascimento, do "estar-a-ser-criança" desde o nascimento, que o processo de governo da "alma" se inicia. É preciso que Emílio aprenda a ocupar-se de si e que o aprenda de acordo com quem o governa numa relação de um para um. Se pensarmos a partir de Emílio, ou Da Educação, o que se verifica é que Rousseau dirige à infância, ao "estar-a-ser-criança", o momento a partir do qual se começa a aprender o governo de si; é na socialização de Emílio com o mestre, e através dela, que se prepara a sua "alma" para se autocontrolar numa lógica de pertença orgânica ao laço social e do laço social à forma de autoridade e de governo (FOUCAULT, 2010, p. 379). Já não se trata de uma autoridade de Estado sobre o sujeito, mas do próprio para consigo, construída a partir de uma relação absolutamente individualizada ante a figura onipresente do mestre. Essa passará a ser a dinâmica que marcará o oficio da infância. Este processo inicia-se no nascimento e deixa de exclusivo do lugar de aluno.

O segundo problema é que Rousseau (autor) escreve sobre a educação de Emílio (criança) por um mestre (Rousseau), para que no futuro seja um adulto à semelhança do que ele (Rousseau, autor e mestre) representa. Ou seja, sempre que fala da criança, fala também do adulto que a governa. Um em espelho do outro.

O terceiro problema é que Rosseau escreve sobre o presente, dirigindo-se ao futuro (à sociedade e à família que idealizou), a partir dele próprio, do que ele representa. Dito de outra forma, ao escrever sobre a infância e sobre a educação da criança "dum povo por vir" (DELEUZE, 1987/1999, p. 14), Rousseau, escreve sobre si e sobre a sua representação de um futuro que era, na verdade, o seu próprio presente.

O quarto é que o processo de educação de Emílio termina quando este representa "o mesmo" que o mestre. Não se trata de um marcador temporal, mas antes de um 
marcador de "mesmecidade". Emílio e Mestre consubstanciam o mesmo adulto quando é assinalado que a autoridade do segundo sobre o primeiro termina e Emílio assume o governo da sua "vontade particular".

Desses quatros eixos de análise decorre que, se pensarmos uma resposta à pergunta "quando é que uma criança deixa de ser uma criança?", encontramos uma ideia que subsiste e que está bem marcada em Emílio: "uma criança deixa de ser uma criança quando é o mesmo, ou seja, quando a relação de poder e autoridade se esbate e termina o trabalho de normalização externa". E isto não ocorre num mesmo momento, nem se assume como uma universalidade, mas antes como uma multiplicidade de reconhecimentos. Se preferirmos, quando o adulto encara e reconhece o "sujeito-criança" como um "sujeito-adulto".

De certa forma, é este o projeto de "obra" comum à família, sociedade e Estado: "a construção e constituição de um adulto que agencia na criança o seu presente (do adulto) como futuro por vir". Não se trata, penso, de um futuro concreto, mas de um futuro feito de "camadas", de multiplicidades, que se sobrepõem na constituição do "estar-a-ser-criança". Como se o presente dos adultos invadisse o "estar-a-ser" da criança produzindo um agenciamento, coletivo e múltiplo, mas também individual e particular, UMA-CRIANÇA-DEVIR-ADULTO que tem no seu interior e em gestação tantas camadas como aquelas que são facilmente reconhecíveis nos adultos. "A criança é o adulto por vir" que materializa uma "atualidade" e uma história. Como Deleuze (2016, p. 363) refere, o "novo é sempre o atual e o atual não é o que somos, mas antes o que devimos, o que estamos em via de devir, ou seja, o Outro, nosso devir-outro".

No fundo, é como se dentro desse escrito de Rousseau fosse possível encontrar ao mesmo tempo um "conteúdo material" e um "conteúdo de verdade" (BENJAMIN, 2016, p. 39) que problematiza o sujeito criança e a sua definição a partir do lugar de adulto a devir. A criança é, em simultâneo, aquilo que existe, mas também aquilo que não existe de forma suficiente. A educação é precisamente uma prática, ou melhor, uma racionalização de uma prática que se vai situar entre um "sujeito-criança" apresentado como dado e um "sujeito-criança" a ser construído.

Por isso, Rousseau oferece-se como um ponto de partida, e não necessariamente inicial, desta pesquisa genealógica sobre os estratos que constituem as infâncias. Em certo sentido, a leitura de Emílio, atravessada pela deriva "o que é uma criança?", permite pensar uma "camada", um estrato da condição "estar-a-ser-criança", que é pautada por um paradoxo constante entre A e B, entre o que é e o que não é, entre presente e futuro. Veja-se que esta dinâmica transporta uma definição do que deve ser o "estar-a-ser-criança", definição essa que encerra dentro de si, parece-me, o dilema do que a infância, do que a criança de cada atualidade e geografia pode devir. "Fala-se do futuro como projeção integral do presente". As variações entre A e B circulam em redor do lugar de onde se fala, e o seu agenciamento individual depende do agenciamento coletivo que se ocupa. Não se trata, por isso, de identificar um agenciamento coletivo único, mas antes de pensar uma multiplicidade de agenciamentos que circulam em torno da premissa UMA-CRIANÇA-DEVIR-ADULTO. Walter Benjamim (2017, p. 121-125) capta isso mesmo quando compara a pedagogia burguesa à pedagogia comunista: do mesmo ao mesmo através da captura constante do diverso. Em certo sentido, "todas as identidades são apenas simuladas, produzidas como um 'efeito' óptico por um jogo mais profundo, que é o da diferença e da repetição [...] independentemente das formas da representação que as conduzem ao Mesmo e as fazem passar pelo negativo" (DELEUZE, 2005 p. 36).

Donde se conclui que há múltiplas "infâncias", tantas como aquelas que se conhecem, reconhecem e se sublimam para o "adulto por vir" que cada um representa. Vive dentro desta ideia uma subjetivação da "alma" operada por tecnologias de governamentalidade (FOUCAULT, 2013, p. 45) que consagram, a cada época, representações sobre o que é a infância, o que é necessário e como se exerce o seu "governo". Esse é, parece-me, o processo pelo qual se opera o agenciamento UMA-CRIANÇA-DEVIR-ADULTO. Não se trata de polarizar as "máquinas abstratas" (DELEUZE, 2007, p. 56) desse governo, nem os governadores da alma, mas pensar, a partir da espiral constitutiva dos indivíduos, que a relação entre adulto e criança reverbera o "agenciamento" uma-criança-"devir"-adulto, o "adulto por vir". Poder-se-á sempre dizer que neste acontecer relacional circulam as ideias de enkráteia (autocontrole) e de aftorrythmisi (autorregulação), que estabelecem os limites da autonomia (autonomia) e da libertāte (liberdade) sob a égide de uma "exemplaridade" adulta.

Antes que os preconceitos e as instituições humanas alterem nossas tendências naturais, a felicidade das crianças, bem como a dos homens, consiste no emprego de sua liberdade; mas essa liberdade, nas primeiras, é limitada pela sua fraqueza. Quem quer que faça o que deseja é feliz, se se bastar a si mesmo: é o caso do homem vivendo em seu estado natural. Quem quer que faça o que deseja não será feliz se suas necessidades ultrapassarem suas forças: é o caso da criança no mesmo estado. As crianças não gozam, mesmo em seu estado natural, senão de uma liberdade imperfeita, semelhante a de que gozam os homens na sociedade. Não podendo prescindir dos outros, todos nós nos tornamos, desse ponto de vista, fracos e miseráveis. Éramos feitos para sermos homens; as leis e a sociedade nos mergulharam novamente na infância. Os ricos, os grandes, os reis são todos crianças que, vendo que se desvelam em aliviar sua miséria, tiram disso uma vaidade pueril e ficam muito orgulhosos com os cuidados que não teriam com eles, se fossem adultos (ROUSSEAU, 1762/1979, p. 54).

De alguma forma, esses conceitos estão presentes num currículo de "verdade" que reverbera num currículo "material". Existe uma espécie de circuito transversal que produz sujeitos como diferentes sendo iguais na ideia da diferença (Ó, 2017). Dito de outra forma, um "currículo de verdade", transversal nas diferentes "máquinas abstratas", com diferentes redações "materiais", que está presente na subjetivação do "ser-criança" que se constitui e vai constituindo na relação com os outros. É ela que 
enquadra a construção da autonomia e da liberdade do "estar-a-ser-criança". De certa forma, é como se existisse uma composição do agenciamento UMA-CRIANÇA-DEVIR-ADULTO que é construída pela sedimentação de ideias normativas e classificativas que delimitam, a cada momento, a infância (isto é normal/anormal; isto é certo/errado; bom/mau) de forma binária. Esta tensão produz, parece-me, a permanente afirmação de "modas" que alavancam a visão que temos do papel das instituições e do que é necessário fazer em cada momento. Fala-se de crianças, mas pensa-se, em pano de fundo, nos adultos que se quer que as crianças devenham. Nas palavras de Rousseau:

É fácil convencer uma criança de que o que lhe queremos ensinar é útil; não basta entretanto convencê-la, é preciso persuadi-la. É em vão que a razão tranquila nos leve a aprovar ou condenar; somente a paixão nos faz agir; e como apaixonar-se por interesses que ainda não se tem? Enquanto a humanidade quase lhe é estranha, não podendo elevá-la ao estado adulto, abaixai para ela o homem à condição de criança (ROUSSEAU, 1762/1979, p. 149).

No entanto, creio que o interesse cada vez maior que as sociedades modernas manifestam pela educação de crianças pequenas encerra em si esta ideia de que, para "cuidarmos do futuro", temos de cuidar de crianças cada vez mais novas, temos de preparar, desde cedo, a criança para aprender o "governo da sua alma", o "governo de si” (Ó, 2006). No fundo, esta representação faz-se presente no desejo que as sociedades modernas têm de que a criança seja mais autônoma, mais autorregulada, mais competente, melhor aluno ou até mesmo no desejo de que se torne um cidadão democrático e participativo, fazendo subsistir um conjunto de práticas que incorporam e materializam a ideia de que a criança se deve aproximar, ao longo do tempo, de uma certa imagem de adulto que representa uma atualidade projetada como futuro.

A "obra" está concluída quando se considera o "sujeito-criança" um igual, quando a autoridade se esbate e se reconhece o outro, já não criança, mas "sujeito-mesmo" que governa a sua "vontade particular" de acordo com a "vontade geral". Sujeitos-mesmo diferentes, mas inteiramente compatíveis a partir da ideia da diferença.

Sintetizando, penso que Rousseau, através de Emílio, ou Da Educação, evidencia um agenciamento UMA-CRIANÇA-DEVIR-ADULTO que é delimitado por tecnologias de governamentalidade que produzem $\mathrm{O}$ MESMO a partir do diverso. Trata-se de um agenciamento que limita as possibilidades do "estar-a-ser-sujeito", transformando-o num "estar-a-ser-criança" que se tornará adulto. Um adulto que representa o lugar que cada um ocupa ou deseja ocupar. Isso mesmo se expressa nas sociedades modernas que, ao aumentarem as respostas institucionais, cada vez mais precoces, sugerem que para o Estado é necessário cuidar, cada vez mais cedo, da infância para salvaguardar, inteiramente, o "adulto por vir". Um adulto que, na multiplicidade constitutiva do que foi o seu "estar-a-ser-criança" e na sua individualidade construída, represente um equivalente integral daquilo que Rousseau chamaria de "vontade geral".

Fractal, Rev. Psicol., v. 30 - n. 3, p. 302-309, 2018
Não perdendo esta hipótese de vista, cabe-nos a nós, família, sociedade e Estado garantir que o lugar da infância é, acima de tudo, um tempo e um espaço que valorize o "estar-a-ser-criança" (descobrir, brincar, questionar), conscientes que existe tempo para concluir o projeto "uma criança devir adulto".

\section{Referências}

ABBAGNANO, N.; VISALBERGHI, A. História da Pedagogia. Lisboa: Livros Horizonte, 1981.

ARIÈS, P. A criança e a vida familiar no Antigo Regime. Lisboa: Relógio de Água, 1988.

BENJAMIN, W. Ensaios sobre literatura. Lisboa: Assírio Alvim, 2016.

BENJAMIM, W. Reflexões sobre a criança, o brinquedo e a educação. São Paulo: Editora 34, 2017.

DELEUZE, G. O ato de criação (1987). Tradução de José Marcos Macedo. Folha de São Paulo, São Paulo, 17 jun. 1999. Caderno Mais!, p. 4-5.

DELEUZE, G. Diferença e repetição. Lisboa: Relógio de Água, 2005.

DELEUZE, G. Conversações (1972-1990). São Paulo: Editora 34, 2008.

DELEUZE, G. Dois regimes de loucos: textos e entrevistas (1975-1995). São Paulo: Editora 34, 2016.

DELEUZE, G.; GUATTARI, F. Mil Planaltos: capitalismo e esquizofrenia. 2. ed. Lisboa: Assírio Alvim, 2007.

FOUCAULT, M. A hermenêutica do sujeito. São Paulo: Martins Fontes, 2006.

FOUCAULT, M. O nascimento da biopolitica. Lisboa: Edições 70, 2010.

FOUCAULT, M. Vigiar e Punir: o nascimento da prisão. Lisboa: Edições 70, 2013.

HADOT, P. O que é a filosofia antiga? São Paulo: Loyola, 1999.

LAPOUJADE, D. Deleuze: os movimentos aberrantes. Tradução de Laymert Garcia dos Santos. São Paulo: n-1 edições, 2015.

MONTAIGNE, M. Três Ensaios: do professorado, da educação das crianças, da arte de discutir. Tradução de Agostinho da Silva. 2. ed. Lisboa: Veja, 1993.

\section{Ó, J. R, do. O governo de si mesmo. Educa: Lisboa, 2006.}

Ó, J. R, do. Seminário de Investigação e Orientação: A Escrita Científica e a Formação Avançada. Relatório da unidade curricular apresentada no âmbito das provas para obtenção do título de agregado, no ramo de conhecimento em Educação do Instituto de Educação da Universidade de Lisboa . Lisboa: Universidade de Lisboa, 2017.

ROUSSEAU, J. J. Emílio, ou Da Educação (1762). São Paulo: DIFEL, 1979.

ROUSSEAU, J. J. The social contract (1762). Londres: Penguin Books, 2004.

Recebido em: 22 de junho de 2018 Aceito em: 25 de setembro de 2018 